\title{
Federal funding for stem cell research: 15 years of indecision
}

Int In the US, the battle over whether to devote government funding to ES cell research has waged since the Dickey-Wicker amendment passed in 1996, banning federal funding of work that involved the destruction of human embryos. In the ensuing years, it has been unclear whether that law applies to research performed on human ES cell lines derived with private funding, and the conflicting policies of the Bush and Obama administrations have left researchers in the field on uncertain ground. Recently, the argument landed in the court system, and in late April of this year, the Federal Court of Appeals for the District of Columbia issued a decision that effectively allows NIH-supported researchers to use established ES cell lines, regardless of their source. The JCI recently spoke to David Scadden (Figure 1), cofounder and codirector of the Harvard Stem Cell Institute (HSCI), about how these shifting policies have shaped stem cell research as well as his visions for the future of the field.

JCI: How do you think that the federal limitations on ES cell research funding affected where we are in stem cell biology today?

Scadden: This area is one that has been very hotly contested since its inception, and there's no doubt that has affected research progress. The issues are very important and have continued to be problematic. The current appeals court ruling is basically just an interpretation of the Dickey-Wicker amendment, which allows federal funding of human ES cell research, but prohibits the destruction of embryos to create human ES cell lines. I think that the instability and uncertainty of funding has had an immeasurable impact on the progress of the science because it's discouraged junior investigators from devoting their careers to this kind of research. We've really lost an entire generation of scientists who could have been working on these questions; we can't know what they might have discovered, or how long it will take us to catch up.

JCI: Do you think a Supreme Court decision is necessary to really settle the legal questions surrounding ES cell research?

Scadden: It's not settled now, that's for sure. The case has gone back to the courts, and it's not clear what the final decision will be; that leaves everyone who works on stem

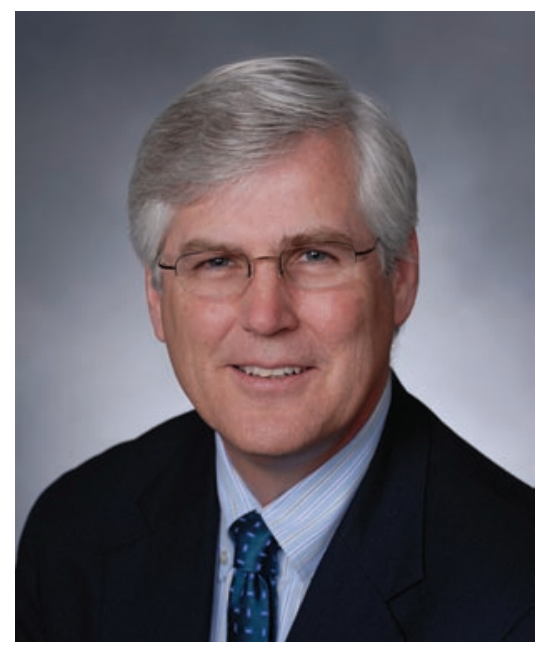

Figure 1

David Scadden.

cells uncertain. Even for us at HSCI, where we're fortunate enough to be able to raise funds to do the work, we have graduate students whose stipend funding is in question. I think what it will really take to settle the question is legislative action ... though given the current political climate, that's unlikely to be forthcoming in the near future.

JCI: Do you think the recent advances in induced pluripotency might have lagged if there had been greater federal support for human ES research projects in the last 15 years?

Scadden: I really don't believe that. The advances in pluripotency were built on John Gurdon's early nuclear transfer experiments, which were the first insight into nuclear reprogramming, performed well before anyone was working on human ES cells.

It's important to keep in mind that ES cells and induced pluripotent stem (iPS) cells are of course very different entities; we're learning that they have different expression patterns and different potentials. Of course the study of ES cells is necessary to define our standard, our understanding of what a pluripotent cell looks like, but I don't think that the advances in iPS cell research happened because people turned away from working on ES cells. The work of Yamanaka, for example, was a great leap forward in pluripotent cell biology, but that work had its own, solid foundation.
JCI: Most of your work is on hematopoietic stem cells. How would federal funding for human ES cell projects affect your current research or your future research plans?

Scadden: I think it doesn't matter whether you work on pluripotent stem cells or multipotent stem cells, adult stem cells or ES cells; the work on each informs the other. When we're talking about understanding how cells are programmed and might be reprogrammed, they're not different sciences, they're like limbs on the same body. So whether or not I use ES cells in my lab, my science will be advanced by research on ES cells.

JCI: Where do you think stem cell research is headed? What do you think will be the next big breakthrough?

Scadden: ES cells as a source for cell therapy was, for a long time, the dominant concept driving the field: ES cells providing a tool to rebuild parts of the body. That is now recognized as a far too narrow lens through which to view the potential for stem cell-based medicine. First, most adult tissues are now recognized to harbor endogenous stem cells. What was a curious aspect of the blood now appears to be the rule for many tissue types, which suggests that by understanding how those cells are regulated, we might be able to enhance their regenerative activity in the setting of injury or disease. Turning on the body's intrinsic repair capability is the basic idea, and studying stem cells in their niche is how to get there, in my view. Second, cell reprogramming is a revolutionary technology that allows us to generate primary human cells that represent the cell type affected by a disease - and we can generate them from the very patient affected. That can become the ultimate personalized medicine tool kit: a stem cell-based tool kit to study what goes wrong, determine what drug candidates might affect it, and possibly even supply the cells to replenish those lost in the disease. So we have a range of options now for thinking about how stem cell biology can become stem cell-based therapies - each of them offers new types of therapies. These are much-needed new arrows in the quiver of future physician-scientists.

\section{Kathryn Claiborn}

